\title{
NARRATIVAS DIGITAIS: CONCEITOS E CONTEXTOS DE LETRAMENTO
}

\author{
NARRATIVA DIGITAL: CONCEPTOS Y CONTEXTOS DE LA \\ ALFABETIZACIÓN
}

\section{DIGITAL NARRATIVES: CONCEPTS AND CONTEXTS OF LITERACY}

\author{
Ana Lúcia PRADO ${ }^{1}$ \\ Ellen Maira de Alcântara LAUDARES ${ }^{2}$ \\ Patrícia Peix oto Carneiro VIEGAS ${ }^{3}$ \\ Ilsa do Carmo Vieira GOULART ${ }^{4}$
}

RESUMO: As atividades de leitura e escrita como práticas sociais ampliam sua esfera de apreensão e atuação em espaços virtuais; vistas além da presença do impresso, determinam modos distintos de agir e interagir nas relações interpessoais. Frente a isso emerge um contexto de múltiplas linguagens circulante nas mídias eletrônicas, o que se impacta diretamente nas relações de ensino-aprendizagem. Diante isso, este artigo assume como objetivo descrever diferentes perspectivas teóricas a respeito do conceito das narrativas digitais, com o propósito de delinear as principais reflexões teóricas da terminologia e da inserção no contexto das práticas de letramentos. Para isso, propõe-se uma reflexão teórica a partir das diferentes concepções sobre narrativas digitais, com base nas discussões de Pierre Lévy (1996, 1999), Walter Benjamin (1983), Almeida e Valente (2012) e Papert (1994), em diálogo com outros autores que discutem a temática. A discussão permite certa consonância entre a conceituação e a dinâmica da globalização, uma tendência que demarca significativamente o processo de construção de conhecimento do indivíduo e sua possibilidade de expressão social e cultural, uma vez que representa as características de um momento histórico, social e cultural.

PALAVRAS-CHAVE: Narrativas digitais. Letramento digital. Ciberespaço. Cibercultura.

RESUMEN: Las actividades de lectura y de la escritura como prácticas sociales amplían su esfera de ataque y performance en espacios virtuales, además de la presencia de opiniones impresas, geram diferentes formas de actuar e interactuar en las relaciones interpersonales. Frente del este, emerge de un contexto de múltiples

${ }^{1}$ Universidade Federal de Lavras, Minas Gerais - Brasil. Mestranda do Programa de Pós-Graduação em Educação. E-mail: ana_luciaprado@hotmail.com

${ }^{2}$ Universidade Federal de Lavras, Minas Gerais - Brasil. Mestranda do Programa de Pós-Graduação em Educação. E-mail: ellenusp@yahoo.com.br

${ }^{3}$ Universidade Federal de Lavras, Minas Gerais - Brasil. Mestranda do Programa de Pós-Graduação em Educação.l. E-mail: patypcr@ @otmail.com

${ }^{4}$ Universidade Federal de Lavras, Minas Gerais - Brasil. Departamento de Educação e do Programa de Pós-Graduação em Educaçã. Doutora em Educação. E-mail: ilsa.goulart@ded.ufla.br. 
idiomas actual en los medios electrónicos, que impacta directamente en las relaciones de enseñanza-aprendizaje. Antes de eso, este artículo asume como objetivo describir las diferentes perspectivas teóricas sobre el concepto de narrativas digitales, con el propósito de delinear las principales reflexiones teóricas de la terminología y la inserción en el contexto de las prácticas letramentos. Para ello, propone una reflexión teórica de las diferentes concepciones de las narrativas digitales, basados en las discusiones de Pierre Lévy (1996, 1999), Walter Benjamin (1983), Almeida y valiente (2012) y un Papert (1994) en diálogo con otros autores que tratan sobre el tema. La discusión permite cierta consonancia entre la conceptualización y la dinámica de la globalización, una tendencia establece significativamente el proceso de construcción de conocimiento del individuo y su posibilidad de expresión social y cultural, ya que representa las características de un momento histórico, social y cultural.

PALABRAS CLAVE: Narrativas digitales. Alfabetización digital. Ciberespacio. Cibercultura.

ABSTRACT: Reading and writing activities as social practices expand your sphere of seizure and performance in virtual spaces, in addition to the presence of printed views, produce different ways to act and interact in interpersonal relationships. That emerges from a context of multiple languages current in the electronic media, what if directly impacts on the teaching-learning relationships. Before that, this article assumes as objective to describe different theoretical perspectives regarding the concept of digital narratives, to outlining the main theoretical reflections of the terminology and the insertion in the context of letramentos practices. To this end, it proposes a theoretical reflection from the different conceptions of digital narratives, based on the discussions of Pierre Lévy (1996, 1999), Walter Benjamin (1983), Almeida and brave (2012) and a Papert (1994) in dialogue with other authors that discuss the subject. The discussion allows certain consonance between the conceptualization and the dynamics of globalisation, a trend that sets significantly the process of building knowledge of the individual and your possibility of social and cultural expression, once that represents the characteristics of a historical, social and cultural moment.

KEYWORDS: Digital storytelling. Digital literacy. Ciberespaço. Cibercultura.

\section{Introdução}

A sociedade contemporânea está marcada pelo desenvolvimento tecnológico, o que a tem caracterizado como a 'sociedade do conhecimento', conforme descreve Olivé (2003). O acesso à informação acontece em tempo real, não se prendendo mais a limites do tempo e espaço, graças aos avanços tecnológicos e à democratização do acesso às Tecnologias de Informação e Comunicação (TDIC). Num processo veloz de retroalimentação, em que se espera cada vez mais pela evolução tecnológica, tais mudanças impulsionam a sociedade a adaptar-se ao novo contexto digital. 
Entretanto, apesar do grande volume de informações disponíveis, não se pode dizer que a sociedade da informação seja a 'sociedade do conhecimento'. Ao contrário da informação, que é adquirida facilmente, o mesmo não pode se dizer do conhecimento. Este é construído antes de ser consolidado e não está acessível para todos. A construção do conhecimento formal passa pelo desenvolvimento de competências e habilidades básicas de leitura, escrita e raciocínio lógico-matemático. Para Olivé (2003, p. 23):

[...] el conocimiento incluye información que es valorada por determinados agentes (epistémicos), que se proponen conocer el mundo, es decir, construir representaciones de él con ciertas características, pero, sobre todo, transformar lo (incluyendo su entorno y a ellos mismos).

Segundo Olivé (2003, p. 23), gerar, adquirir e usar o conhecimento possui uma dimensão prática, visto que “[...] la generación misma de conocimiento constituye ya una forma de transformación del mundo mediante acciones”. Um espaço culturalmente determinado para a mudança de ações, por meio da aprendizagem formal, é a escola, que o faz utilizando-se de metodologias que atendam à intencionalidade no ato de ensinar. O processo de aprendizagem segue padrões pré-determinados, que muitas vezes transformam a aprendizagem em mera imposição e depósito de conteúdos prédeterminados, descontextualizados da realidade dos sujeitos nela envolvidos.

Apesar da inserção física dos equipamentos, observa-se que a inclusão das TDIC no cotidiano escolar ainda é um desafio, pois exige uma mudança metodológica para que seu uso se reflita numa aprendizagem eficiente. Observa-se que, no cotidiano escolar, esses recursos tecnológicos ainda não têm sido explorados como deveriam, em parte pela falta de conhecimento dos professores quanto ao seu uso como instrumento ativo no processo de aprendizagem, e não como mais um recurso pedagógico estático.

Por considerarmos que o processo de leitura e escrita ganha dimensão sociais diferenciadas, o que requer dos professores uma compreensão deste contexto dinâmico e interativo da linguagem nas mídias eletrônicas, este texto assume como objetivo descrever diferentes perspectivas teóricas a respeito do conceito das narrativas digitais, com o propósito de delinear as principais reflexões teóricas, tanto da terminologia, quanto do como as narrativas digitais estão inseridas no contexto do letramento.

Em busca de esgrimir uma abordagem teórica, especificamente, acerca da conceituação de narrativa digital, o texto esbarra em conceitos como 'sociedades orais e 
escritas' de Weber (2014), 'construcionismo' de Papert (1994) e 'cibercultura e ciberespaço’ de Lévy (1996; 1999).

Ao pensar em quais reflexões podem ser apontadas a respeito do que se compreende por narrativas digitais, realizou-se um levantamento de autores que tratam da temática, por meio de revisão bibliográfica. Neste percurso investigativo, foram encontrados cinco registros, no período entre 2013 e 2017, no portal internacional Eric, Institute of Education Scienses, através dos descritores 'digital storytelling' e 'digital literacy’. O enfoque destas publicações, além de dissertarem acerca das narrativas digitais e do letramento digital, ampliavam a discussão sobre as competências do século XXI e o engajamento necessário aos estudantes, o engajamento dos profissionais em contar histórias digitais, a literatura digital como práxis social: os desafios, as interseções, as novas literaturas e suas epistemologias, a construção do conhecimento acadêmico e o desenvolvimento do currículo multimodal, ou web currículo, e por fim, a mídia social e o novo ambiente acadêmico: os desafios pedagógicos.

Apesar do foco das pesquisas serem as narrativas digitais, os artigos seguem dimensões diferenciadas no contexto argumentativo, percebe-se pouco adentramento à conceituação e à reflexão teórica do termo.

Diante isso, este texto apresenta uma reflexão teórica a partir das diferentes concepções sobre narrativas digitais, com base nas discussões de Pierre Lévy (1996; 1999), Walter Benjamin (1983), Almeida e Valente (2012) e Papert (1994), em diálogo com outros autores que discutem a temática.

Para melhor compreensão da temática disposta, a reflexão teórica se dividirá em três momentos: no primeiro se fará uma ponderação entre as narrativas tradicionais em proximidade às narrativas digitais; no segundo, busca-se uma descrição das narrativas digitais no ciberespaço e no terceiro tem-se a discussão a respeito das narrativas em contexto de letramento digital.

\section{Das narrativas tradicionais às narrativas digitais}

Narrar histórias é uma tendência natural do ser humano, sendo uma forma considerável de estabilidade cultural e uma relevante ferramenta de aprendizagem, conforme sinaliza Bruner (1990). Ao narrar um episódio, o narrador expõe sua maneira de ver o mundo, de modo que narrar torna-se uma sistematização da experiência para a 
compreensão do fato ocorrido, assim como também ocorre com o receptor ou ouvinte. Narrar e ouvir não são ideações livres, visto que englobam o saber, a racionalidade e a identidade de como se percebe o mundo.

Nesta perspectiva, o ato de contar uma mesma história, por mais que os ouvintes e os narradores sejam os mesmos, faz com que se deixem registradas as experiências de vida e as respectivas reações diante do fato narrado, sempre havendo mudanças entre uma história e outra, seja esta alteração de percepção, de narrador, de local ou tempo. Com a utilização das novas mídias digitais, as narrativas medraram-se, fusionando características da narrativa escrita e oral e sendo complementadas com a coautoria dos 'interatores', que por sua vez podem participar de forma ativa e interativa da elaboração das histórias e de seus desfechos.

As narrativas apresentadas em hipermídia amalgamam peculiaridades das narrativas escritas e orais, podendo ser alternadas entre lineares e não lineares, cronológicas e não cronológicas. O primordial, segundo Weber (2014), na tradição oral, não é a sequência, nada obstante, elaboração interativa, assimilando-se em alguns pontos com os hipertextos.

Desta forma, o ato de narrar histórias também se altera diante das inovações tecnológicas, o que demanda maior interatividade, troca de conhecimentos, autoria e ludicidade. As mídias digitais podem colaborar para com o Letramento e formação do leitor, uma vez que o indivíduo letrado é apto a confrontar textos das mais distintas linguagens, tornando-se um leitor ávido de palavras, gestos e ações do mundo que o cerca.

Segundo os estudos de Paiva (2007), com o surgimento das tecnologias computadorizadas, emergem diferentes formatos de produção de texto nas práticas sociais da linguagem, dentre elas, as narrativas multimodais ou multimídias. Do ponto de vista de Vasconcelos e Magalhães (2010), as tecnologias possibilitam a incorporação de diferentes meios, contudo, elas mantêm a sua finalidade, ou seja, sua elaboração dos elementos básicos, como o tempo, o espaço, o narrador, a personagem e o enredo; estes são quase inalteráveis, mesmo havendo mudanças consoantes à mídia utilizada.

A era digital teve significativo desenvolvimento no último quarto do século $\mathrm{XX}$, conforme nos mostra Murray (2011). Por volta dos anos 70, os valores dos computadores tornaram-se mais acessíveis, o que possibilitou uma maior conexão entre os computadores, progressivamente mais eficientes e velozes, numa taxa exponencial de 
aperfeiçoamento; consubstanciando-se em um único suporte, potencializam as tecnologias de comunicação e de representação, antes distintas.

O computador em rede opera como um telefone, visto que oportuniza a comunicação pessoa a pessoa em tempo concreto, assim como uma televisão ao propagar filmes; uma biblioteca, ao ofertar seu acervo; um museu, em sua metódica apresentação de informações visuais; como um aparelho de rádio; um quadro de avisos; um tabuleiro de jogos; ou mesmo um manuscrito, ao recriar os cilindros de textos dos pergaminhos (MURRAY, 2011).

O universo digital incorpora todo o tempo, mais recursos de representação, à medida que os estudiosos objetivam construir dentro dele uma realidade virtual tão consistente e abundante quanto a própria realidade. $\mathrm{O}$ desenvolvimento técnico e financeiro desse meio de comunicação concebeu diferentes entretenimentos narrativos, que se diversificam desde os videogames até os hipertextos literários pós-modernos, como blogs, WhatsApp, Facebook, entre outras redes sociais. Este extenso ramo de arte narrativa conduz consigo a expectativa de um novo meio de expressão na mesma diversidade dos livros impressos e dos meios televisivos. Para o livro impresso, foram necessários mais de 50 anos de experimentação até que se constituíssem alguns padrões, como, por exemplo, as fontes legíveis, a numeração de páginas, o uso adequado de parágrafos no texto, a divisão de capítulos, etc.

Walter Benjamin (1983, p. 60) indica o declínio da narração no início da Idade Moderna, com o surgimento da imprensa e o advento do romance, desdobrando o pensamento para o que difere um gênero do outro, em que o;

[...] o narrador colhe o que narra na experiência, própria ou relatada. E transforma isso outra vez, em experiência dos que ouvem sua história. $\mathrm{O}$ romancista segregou-se. O local de nascimento do romance é o indivíduo na sua solidão.

Então, a concepção das narrativas digitais passa a ocorrer através de um processo de produção textual, que se apropria do carácter recente dos processos audiovisuais e tecnológicos aptos a inovar o ato de contar histórias, configurando-se em um instrumento pedagógico eficaz e motivador, ao passo que agrega, à prática docente, a proximidade entre a realidade vivida também fora das salas de aula.

Atualmente, na era do desenvolvimento da narrativa computadorizada, é notória a pressão dos limites da linearidade nos livros, nos filmes e nas peças teatrais. As histórias que emergem assumem múltiplas formas; conforme Murray (2011), o termo 
'História Multiforme' é utilizado para designar a narrativa escrita que exibe um único fato ou enredo em múltiplas versões. Parcela do arrebatamento por detrás do aumento das histórias multiformes vem dos estudos da Física, em que a compreensão de espaço e tempo não são fatos irrefutáveis.

Desta forma, a diversidade de narrativas multiformes exprime o esforço de se exteriorizar uma percepção da vida enquanto constituição de possibilidades paralelas, ou seja, a narrativa multiforme busca significar uma existência concomitante às possibilidades, assentindo ter em mente, simultaneamente, copiosas e paradoxais alternativas. Conforme Murray (2011, p. 50),

Seja a história de múltiplas formas um reflexo da física pós-einsteiniana, ou de uma sociedade secular assombrada pela imprevisibilidade da vida, ou de uma nova sofisticação no modo de conceber a narração, suas versões alternadas da realidade são hoje parte do nosso modo de pensar, parte da forma como experimentamos o mundo. Viver no século XX é ter consciência das diferentes pessoas que podemos ser, dos mundos possíveis que se alternam e das histórias que se entrecruzam infinitamente no mundo real. Para apreender um enredo que se bifurca constantemente, entretanto, é preciso mais do que um denso romance labiríntico ou uma sequência de filmes. Para capturar de fato essa cascata de permutações, é preciso um computador.

Artistas digitais independentes utilizam a rede como um conjunto universal de propagação da arte, inserindo animações, histórias ilustradas, histórias hipertextuais e, inclusive, filmes digitais de curta metragem. As narrativas de ficção científica e fantasiosa emergem no ciberespaço. Contudo, os elementos documentais da web, como exemplo, os diários de viagem, os álbuns de família e as autobiografias visuais do âmbito digital, têm levado a narrativa digital a se aproximar da narrativa multiforme (MURRAY, 2011).

As tradicionais narrativas orais e escritas hoje são elaboradas com a interposição de diferentes mídias, o que colabora para que uma atividade se torne densa e aprimorada. As narrativas não foram subitamente debandadas de sua linearidade para configurarem um molde multifacetado do meio virtual.

Robin (2006) segmenta as narrativas digitais em três esferas, que são os documentários, as narrativas pessoais e as histórias informativas. As narrativas pessoais configuram-se naquelas em que o foco se encontra na exposição de ocorrências expressivas da vida de alguém, ao passo que os documentários históricos objetivam a compreensão dos fatos pretéritos, alicerçados em fatos históricos, enquanto as histórias 
informativas visam à transferência de uma mensagem otimista, que instrui o ouvinte, acarretando em uma alteração na qual os elementos narrativos se correlatam com a respectiva cultura. As narrativas evoluíram dos meios analógicos e foram impulsionadas pelas oportunidades provocadas pelas mídias digitais. Os predecessores das narrativas digitais foram as histórias multiformes que concediam subdivisões do enredo da história principal que oportunamente alternavam-se, seja quanto ao ponto de vista ou dos episódios da história, existindo, assim, distintos desfechos para a narrativa.

De acordo com Almeida e Valente (2012), esses recursos oportunizam variadas formas de elaboração de narrativas digitais. Os elementos que constituem a narrativa mídia, ação, relacionamento, contexto e comunicação, apontados por Paul (2007), corroboram com a teoria de Murray (2011), em se tratando da utilização das mídias e tecnologias digitais no momento de criação de um enredo, no exercício que agrega os contextos descritos pelo autor, na interlocução que consente ao leitor interagir com o narrado.

Bruner (2001) associa o ato de narrar a uma sistematização da experiência, para que se compreenda o fato ocorrido e se promova uma nova maneira de contá-lo, enquanto para Cunha (1997) a narrativa é um prosseguimento de eventos e episódios abarcando os humanos como personagens, em um contexto específico, no tempo do fato ocorrido, possibilitando o ato de prosseguir ou recuar no tempo, em consonância com as intenções e significados almejados, que compreendem as relações entre cultura e mente do sujeito, consigo e com os outros.

Desta forma, para Almeida e Valente (2012), as narrativas não são ideações livres, visto que englobam o saber, a racionalidade e a identidade de como as pessoas percebem o mundo. Existe hoje uma pluralidade de meios de produção de narrativas digitais; são elas: narrativas interativas, histórias digitais, relatos digitais, narrativas multimídias ou narrativas multimidiáticas, que permitem também a criação não linear das histórias.

Considerando a estrutura composicional do gênero, Lemke (2002) descreve que as narrativas digitais configuram-se fundamentalmente em uma trama linear, em que os elementos empregados são inalteráveis, conforme relatos tradicionais, ou podem utilizar mecanismos de hipermodalidade, quando diferentes categorias se integram na hipermídia, tornando-se não lineares e não cronológicas, possibilitando ao leitor escolhas quanto ao percurso a ser seguido, o que permite a cada inovação de versão o seu armazenamento. 
As novas tecnologias ampliaram as possibilidades narrativas, incluindo recursos de som, imagem e técnicas variadas; usualmente, a estas narrativas, dá-se o nome de narrativas digitais ou histórias multimodais. As narrativas digitais possuem alguns elementos estruturais, como enredo, narrador, personagens, espaço, tempo. De modo que a história, o que vai ser contado, assim como em tempos passados era feito no entorno da fogueira, as narrativas digitais harmonizam vozes, sons, textos, imagens, vídeos e diferentes recursos tecnológicos para elevar a experiência sensível do leitor e aproximá-lo o máximo possível da realidade. O leitor irá interagir com a história de acordo com seus próprios comandos. Por haver distintas formas de se narrar e combinar os recursos tecnológicos, a potencialidade das narrativas digitais permite dar vazão à interatividade e à criatividade.

Em concordância com Robin (2008), uma narrativa digital é constituída por sete elementos básicos, que são: o ponto de vista, que seria a visão do autor em relação ao fato narrado, a questão dramática, que se configura no problema central da trama e que cativa o público, o conteúdo emocional, que permite a identificação entre autor e "interator", o poder da voz, quando o narrador fomenta a compreensão da narrativa, o fundo musical, elemento de enriquecimento da narrativa, a economia, estratégia de apresentar um número restrito de informações por slide para que o público permaneça atraído pelo enredo e por fim, ritmo e entonação, que é a forma que ocorre a narrativa até o seu desfecho, ora apresentando-se rapidamente, ora podendo ser lenta. As narrativas digitais então podem ser concebidas através de orientações que se articulam de forma completiva, que são: um conjunto de cenas fixas, podendo variar entre grafismo ou fotografias, ou união de ruídos, palavras, silêncio ou sons, alternando entre conjunto visual ou sonoro.

Segundo Murray (2011), os ambientes digitais podem ser procedimentais, ou seja, são resultantes do pensamento algorítmico de comportamento e das regras. Participativos, visto que provêm de reconstituição codificada de respostas comportamentais. Espaciais, uma vez que há o processo interativo da navegação. Enciclopédicos, devido à capacidade de armazenamento de dados. As narrativas digitais se desenvolvem essencialmente por meio da Imersão, que é a permissão para ser vivida a fantasia, possibilitando uma proximidade entre real e virtual; segundo Lévy (1996), o espaço virtual é um ambiente real. Todas as criações virtuais pressupõem uma reprodução da realidade, contudo, limitada, e pode não corresponder com o mundo 
físico. A agência, que se configura na capacidade de realização das ações e participações do leitor, e a transformação, que torna o ambiente mais plástico e passível de alterações.

\section{Narrativas digitais no ciberespaço}

O ciberespaço é o local em que os indivíduos estão mergulhados, entrosados, sintonizados, conforme descreve Lévy (1999, p. 17), num ambiente em que abordam seus pensamentos, expressam suas opiniões, enfim é “[...] o espaço de comunicação aberto pela interconexão dos computadores e das memórias dos computadores”, ou seja, a possibilidade e facilidade que hoje temos de 'dar', 'receber', 'compartilhar' informações e opiniões em diversos lugares e/ou momentos; de modo que fiquem registradas na vasta memória e no complexo sistema de redes. Ainda, segundo Lévy (1999, p. 126), o ciberespaço que surgiu a partir do movimento social iniciou muito antes da chegada da internet, na década de 80, com as diversas mídias clássicas (bibliotecas, museus, jornais, televisão, etc.), “[...] como uma prática de comunicação interativa, recíproca, comunitária e intercomunitária".

Os indivíduos manifestam diferentes técnicas, opiniões, práticas, atitudes, expressões, pensamento e valores nessa rede mundial de computadores, que se caracteriza como sendo a cibercultura, e se apresenta em uma multiplicidade de modos de comunicação, de expressão e interação social, criando espaços diferenciados de práticas de leitura e escrita no desenvolvimento das narrativas digitais. (LÉVY, 1999)

A cibercultura não vem para substituir os livros, os quadrinhos ou outros gêneros textuais, mas sim, segundo Lévy (1999), para permitir que a partir da utilização de três princípios que representam esse fenômeno, as narrativas digitais sejam significativas no processo de ensino-aprendizagem; são denominadas pelo autor como: a interconexão, as comunidades virtuais e a inteligência coletiva.

Destaca-se entre elas a inteligência coletiva, pois, para Lévy (1999), será a partir da participação dos sujeitos ou grupos de diferentes culturas, situações econômicas e sociais, que se possibilitará a construção de um espaço dinâmico e personalizado, viabilizando a interação social, superando a barreira do tempo e espaço. Todavia, alguns grupos acabam por perder a essência da inteligência coletiva, levando-a para o lado da dominação em massa e perpetuação da exclusão social, que se torna um retrocesso no 
processo de formação dos sujeitos, o que requer, portanto, uma aplicação cuidadosa deste princípio em busca da emancipação do homem.

O ciberespaço torna-se um local de intensa produção textual, em que os sujeitos criam e recriam práticas de leitura escrita a partir da hipermodalidade; surgem narrativas multiformes. Se, segundo os estudos de Prado e Soligo (2005, p. 3), a narrativa vem do latim narrare que significa "[...] contar, relatar, narrar. E se aproxima do que os gregos antigos clamavam de épikos - poema longo que conta uma história e serve para ser recitado", a vida real passa a ser narrada em espaços virtuais, entre uma linguagem verbal e não-verbal; formam-se textos híbridos.

Assim, as sociedades passaram a narrar histórias e fatos para transmissão de saberes, comunicação, além da preservação de uma dada cultura. Para Bakhtin (1999, p. 156), o discurso narrativo "[...] procura desfazer uma estrutura compacta e fechada do discurso citado", o que permite criar uma situação dialógica com outrem. Hirschkop (2010, p. 94) comenta que Bakhtin compreende que o dialogismo como;

[...] ato histórico: não uma significação de uma realidade estática de um sujeito solitário, mas uma intervenção discursiva ativa, condicionada por circunstâncias sociais e históricas precisas.

Para Lévy (1999, p. 114), com a comunicação escrita, a narrativa subsiste "fora de suas condições de emissão e de recepção, as mensagens escritas mantêm-se 'fora de contexto". Portanto, condiciona as narrativas a serem universais e imutáveis. Independente das modalidades escolhidas, se escrita ou oral, para contar/descrever histórias e fatos, ambas têm seus destaques, particularidades ou estilos, que irão influenciar a narrativa digital.

A universalidade não implica na totalidade, pois Lévy (1999, p. 151) explica que o ciberespaço surge "para todos"; no entanto, a diversidade cultural e pluralidade de ideologias não percorrem o mesmo caminho, mas continuam com sua identidade, apesar das influências. As narrativas digitais, como outras realidades virtuais, apresentam 3 formas principais e dependentes, o texto, a música e a imagem, e “[...] ilustram um princípio de imanência da mensagem ao seu receptor que pode ser aplicado a todas as modalidades do digital: a obra não está mais distante, e sim ao alcance da mão. Participamos dela, a transformamos, somos em parte seus autores".

Vale ressaltar que, para Lévy (1999, p. 200), as obras são "abertas", ou seja, haverá um autor para direcionar a ideia principal, mas serão os "exploradores" que 
organizarão os caminhos a percorrer, através dos hipertextos ou do "metamundo" virtual da web.

As narrativas digitais insurgem como uma forma alternativa ao modelo tradicional de educação, em que a partir de novas competências e habilidades, o indivíduo consiga assimilar os signos no processo de alfabetização e letramento, entendendo que no letramento digital:

As narrativas, que obedeciam a ordens cronológicas e a fórmulas mnemônicas, ganham novos contornos [...] Cada uma dessas possibilidades, quando vivida e manipulada, passa a fazer parte de um repertório, preferencialmente aberto, de um leitor que soma experiências. E a gama de experiências e os cruzamentos que o leitor pode fazer entre elas no reconhecimento de novos objetos de ler ou de escrever, os usos mais ou menos versáteis que o leitor/escritor faz dos materiais e veículos que conhece e deseja conhecer fazem parte do que se denominou letramento. (RIBEIRO, 2014, p. 134)

O letramento digital se constitui de práticas diferenciadas de uso da leitura e da escrita, de modo que os dispositivos eletrônicos despertam novas formas de organizar o conhecimento (LÉVY, 1999). A partir deste processo cooperativo e interativo, o indivíduo é sujeito do seu processo de construção de seu conhecimento, já que as mídias digitais como internet, aplicativos, permitem que ele próprio busque, opte, opine sobre os meios e conteúdo. Quando o indivíduo avalia os recursos utilizados, eles passam a ter oportunidade de personalizar os dispositivos, de modo que os tornem "naturais".

Para Lévy (1999), o acesso às narrativas digitais, através de softwares, apresenta uma interface simplificada, além de serem disponibilizados programas gratuitos. As novas ferramentas das narrativas digitais mudam a forma de produção da leitura e escrita do indivíduo; isto também ocorreu num processo histórico da troca do pergaminho pelo livro. Agora os produtores irão repensar e reprojetar os dispositivos digitais de acordo com a demanda dos leitores, que buscam conforto, eficiência, eficácia, portabilidade e compreensibilidade, segundo Ribeiro (2014).

As narrativas digitais aparecem a partir da interconexão e de comunidades virtuais, que se utilizam da inteligência coletiva para expressar a cultura dos jovens, adultos e crianças no âmbito da leitura. Os livros digitais, suas interfaces e softwares de literatura não surgem para substituir os recursos já existentes, representam um multiplicador e incentivador para o acesso à "realidade virtual”; segundo Lévy (1999, p. 47), o virtual pode ser aquilo que existe apenas em potência e não em ato. 


\section{Letramento digital: a leitura e a escrita a partir da visão 'construcionista'}

Nomeia-se por letramento, conforme Soares (2002, 2004), a circunstância em que um indivíduo seja capaz de ler e escrever e saber fazer o uso social desta escrita e leitura. De acordo com a autora, com o uso da tela como novo suporte de leitura e escrita, surgem novas formas de acesso à informação e ao conhecimento e, consequentemente, a diferentes maneiras de ler e escrever. A estas diversas práticas sociais de leitura e escrita inseridas na cibercultura chamamos letramento digital.

Letramento digital caracteriza-se por um dentre diversos tipos de letramento, sendo utilizado ao domínio das tecnologias digitais, pelo apoderamento dos sujeitos sobre os instrumentos de comunicação com a utilização dos recursos tecnológicos.

Segundo Xavier (2002, p. 2), o letramento digital prognostica o domínio das ferramentas digitais, assegurando práticas letradas e outorgando sentido ao que foi escrito e lido em uma tela, demonstrando habilidades de compreensão de imagens, sons, seleção e apreensão de informações, visto que "[...] ser letrado digitalmente pressupõe assumir mudanças nos modos de ler e escrever os códigos e sinais verbais e não-verbais, como imagens, desenhos, se compararmos às formas de leitura e escrita feitas no livro, até porque o suporte sobre o qual estão os textos digitais é a tela, também digital".

A expansão comunicativa que as tecnologias digitais possibilitam oportuniza diferentes alternativas de leitura e escrita, propiciando o uso de processadores de texto, até mesmo a capacidade de navegação dentro de um texto, configurando-se uma ruptura da leitura tradicional.

A simplicidade da manipulação de imagens e texto transmutam a forma de produção, compreensão e interpretação das linguagens verbais e visuais. Santaella (2004) constatou que usuário de hipermídia faz uso de diferentes habilidades daquele leitor de texto impresso, bem como leitores de cinema ou televisão. A recognição de que as tecnologias digitais requerem diferentes habilidades, e desta forma, requerem o trabalho de diferentes letramentos, propelindo novos desafios educacionais, o que requer maior conhecimento para com os recursos digitais, sejam eles as redes sociais, o processador de texto, a internet, lista de discussão (VALENTE, 2001).

Ao dissertar acerca do letramento digital é possível realizar a associação com a integração curricular, que é uma incumbência laboriosa. Aqueles que perfilham a visão “construcionista" dos usos dos artefatos digitais alvidram a constituição de ambientes de 
aprendizagem apoiados em uma combinação de mídias, em que os usuários conciliam o tradicional com o tecnológico.

Considerando que, segundo Seymour Papert (1994), o uso do computador pode ser compreendido como ferramenta de aprendizagem, a utilização das mídias digitais implicaria num novo modo de aprender, inserido em um novo ambiente, o ciberespaço.

De acordo com Nunes e Santos (2013), o ciberespaço é o espaço de aprendizagem onde as Tecnologias Digitais de Informação e Comunicação (TDIC) estão inseridas, e apresentam novas possibilidades de aprendizagem, através da adoção de novas metodologias. Dentre essas diferentes metodologias, destacamos em especial o "construcionismo".

Para Papert (1994, p. 134), o "construcionismo" é uma filosofia educacional definida como o ato de "[...] ensinar de forma a produzir a maior aprendizagem a partir do mínimo de ensino". Nela, o melhor caminho para a aprendizagem é a construção do conhecimento, e não apenas o aprimoramento dos métodos de instrução. Em outras palavras, ao analisar os processos e habilidades envolvidos na construção de conhecimento pelo indivíduo, propõe-se que a consolidação da aprendizagem decorre de conhecimentos prévios adquiridos pelo sujeito, e da sua interação com os meios concretos de que dispõe para aprender.

Um dos meios concretos propostos e defendidos por Papert (1994) é a efetiva utilização do computador nas escolas. Entretanto, vale ressaltar que a inserção das TDIC no meio educacional traz consigo uma mudança profunda nos processos de apropriação da leitura e escrita por meio do letramento digital, uma vez que "[...] diferentes espaços de escrita e diferentes mecanismos de produção, reprodução e difusão da escrita resultam em diferentes letramentos", segundo descreve Soares (2002, p. 156).

Para esse ambiente da cibercultura, utilizam-se outras formas de estruturas textuais, como os hipertextos, em que o espaço de escrita é multilinear, multissequencial, sem ordem nem unidade pré-temporal, conforme Soares (2002). Por se tratar de um processo individual, a construção das relações de sentido numa narrativa digital é elaborada a partir da sua própria reflexão acerca da construção dos conceitos.

Schwambach (2016) aponta que as narrativas digitais permitem uma aprendizagem colaborativa, promovem o desenvolvimento de competências e habilidades de leitura e escrita, além de desenvolver a criatividade e a autonomia do indivíduo. 
Ao privilegiar a autonomia e ressignificar a importância da aplicação prática do conhecimento escolar no contexto de vida do aluno, o "construcionismo" vai ao encontro da educação emancipadora da teoria de Paulo Freire (1987), conforme destaca Papert:

[...] na vida, geralmente o conhecimento é adquirido para ser usado. Todavia, a aprendizagem escolar, com maior frequência, encaixa-se na apropriada metáfora de Paulo Freire: nela o conhecimento é tratado como dinheiro, para ser guardado em um banco para o futuro. (PAPERT, 1994, p. 60).

Assim, uma vez que o objetivo do "construcionismo" é a construção do conhecimento, e não apenas a transmissão e acúmulo de conteúdos, destaca-se que a aprendizagem consolida-se na interação. Nesse novo modelo, os alunos passam a ser sujeitos ativos no processo de aprendizagem e o professor assume o seu papel como mediador. Para tanto, novas posturas e habilidades são exigidas de ambos, como por exemplo:

[...] a colaboração e a construção conjunta; a atividade criativa; a exploração da informação, promovendo a aprendizagem por descoberta; um novo perfil de aluno, um aluno construindo ativamente a sua aprendizagem; a possibilidade de manter a individualidade, através de ferramentas que levem em conta as características individuais dos alunos. (CARNEIRO et. al, 2005, p. 2)

De acordo com Azevedo (2008, p. 25), ao comentar a concepção de Papert (1994), descreve que a construção e a consolidação do aprendizado no uso de narrativas digitais devem basear-se nas cinco dimensões do "construcionismo": dimensão pragmática, dimensão sintônica, dimensão sintática, dimensão semântica e dimensão verbal.

Para Azevedo (2008, p. 25), a dimensão pragmática caracteriza pela ideia de que: “[...] as construções mentais devem ser apoiadas por construções concretas”. Nesse sentido, o aluno deve ter clareza da utilização prática e imediata do conhecimento que está sendo produzido.

A dimensão sintônica, conforme Azevedo (2008), refere-se ao uso de estratégias didáticas, em que destaca que a utilização de projetos significativos para os alunos. Quando um tema parte do centro de interesse do aluno, a aprendizagem ocorre com mais naturalidade, ao contrário de conteúdos impostos pelo currículo que, muitas vezes, estão totalmente desconectados da realidade do aluno. 
A dimensão sintática, de acordo com Azevedo (2008, p. 26), refere-se à necessidade de uso, ou seja, torna-se essencial que os alunos tenham "[...] acesso fácil aos elementos básicos do ambiente de aprendizagem e progressão na manipulação desses elementos, de acordo com sua necessidade e desenvolvimento cognitivo". Embora reconheça que há limitações para esse acesso em sua totalidade, essa dimensão deve ser considerada, na medida do possível.

A dimensão semântica aponta que a construção de conceitos ocorre desde que os materiais ofereçam múltiplos significados. A experimentação desses significados transcende o conceito abstrato, o que contribui para a consolidação da aprendizagem.

Na dimensão social, finalmente, o envolvimento e o sentimento de pertença são as chaves de todo o processo de construção do conhecimento, seja ela entre indivíduos ou entre os indivíduos e o objeto de conhecimento. Assim, Azevedo (2008, p. 26-27) ressalta que essa consolidação do conhecimento ocorre com mais facilidade quando há uma conexão entre “[...] as pessoas, a cultura local e os trabalhos envolvidos".

A utilização das narrativas digitais como instrumento de desenvolvimento das habilidades de leitura e escrita e construção do conhecimento reforça as ideias preconizadas por Papert (1994) na sua filosofia "construcionista", pois o aluno torna-se autônomo, construtor do próprio conhecimento na interação com todos os elementos do processo de aprendizagem.

Além disso, por suas características, as narrativas digitais apresentam-se como um atrativo para os alunos, que se encontram imersos na cibercultura. A motivação natural decorrente do uso dos recursos tecnológicos na educação é um diferencial que concorre para a melhoria da aprendizagem, pois o objeto de conhecimento já está inserido no contexto cultural do aluno, possibilitando o acesso a conhecimentos que automaticamente autorizam a inclusão na sociedade digital.

\section{Considerações finais}

Com finalidade de descrever diferentes perspectivas teóricas a respeito do que se compreende por narrativas digitais, buscou-se a partir de uma reflexão teórica demarcar o conceito de narrativa digitais e sua relação com o contexto de letramento, uma reflexão que esbarrou em discussões a respeito da arte narrativa. 
Narrar histórias tem uma relação direta com os romances, poesias, contos, prosas e os mais diversos gêneros textuais e abarca o saber, a raciocínio, a identidade e a forma pela qual as pessoas constituem e compreendem o conhecimento acerca de si e dos outros. As narrativas tradicionalmente orais e escritas passam a ser encontradas nas mais diversas mídias digitais. Em um único artefato digital é possível constatar diversos recursos, como exemplo, jogos, câmera fotográfica, câmera de vídeo, gravador de áudio e outros, o que proporciona distintos meios de produção de narrativas, para além do contado ou escrito. Ademais, emergem distintas formas de se produzir um texto, procedentes das práticas sociais das linguagens midiáticas. Desta forma, as narrativas digitais se constituem na junção entre o ato de se contar uma história em um contexto de multimídia. Em síntese, apresenta-se como o ato de utilizar-se dos artefatos digitais para se narrar histórias.

Deste modo, os autores estudados convergem na indicação de que o uso do computador como recurso didático-pedagógico, ou seja, como instrumento de aprendizagem, a ser utilizado com a mediação do professor, permitirá que os sujeitos utilizem múltiplas formas de leitura e escrita, de modo a contribuir para o processo de produção de conhecimento por meio de uma aprendizagem cooperativa e interativa. Ao tornar-se autor da sua aprendizagem, o aluno instaura-se um ser e fazer autônomo e reflexivo, potencializando o senso crítico.

O uso do computador apresenta diferentes possibilidades de ler e escrever, uma vez que a própria estrutura das práticas de leitura e escrita adaptou-se ao contexto dos novos suportes digitais. É nesse contexto que as narrativas digitais se mostram um objeto tanto de interesse para a área acadêmica, ao aprofundar conhecimentos como um objeto de estudo e análise, quanto objeto merecedor dos olhares aguçados da área educacional, como recurso pedagógico, uma vez que apresentam características próprias que a tornam atrativas e desafiadoras no processo do letramento digital.

A reflexão teórica sinaliza que o recurso pedagógico, por meio das narrativas digitais, torna o sujeito ativo no processo de construção, pois é capaz de tecer a sua trilha de conhecimento, interagindo com os outros atores do processo - com os seus pares, com o seu próprio conhecimento prévio, com os novos conceitos que lhe são apresentados e com o seu mediador - num processo de aprendizagem colaborativa.

Por sua característica dinâmica, as narrativas digitais apresentam-se como motivadoras para os alunos e desafiadoras para os professores, que terão que adaptar-se a um novo ambiente de aprendizagem. $\mathrm{O}$ uso de narrativas digitais induz à criatividade, 
à autonomia e à participação, algo que sempre buscamos em nossos discursos pela educação de qualidade, mas que, ainda, encontram-se num plano teórico na realidade escolar.

A compreensão conceitual e a efetiva utilização das narrativas digitais como recursos para o desenvolvimento e consolidação de habilidades de leitura e escrita ainda são desafios, que devem ser superados aos poucos, no processo de formação inicial e continuada de professores. Além do aspecto formativo, é necessária a mudança de aspectos estruturais e conceituais da escola como a conhecemos, uma vez que se encontra desconectada das novas demandas sociais advindas do contexto da cibercultura, um assunto que abre espaço para outras reflexões teóricas.

\section{REFERENCIAS}

ALMEIDA, M. E. B.; VALENTE, J. A. Integração currículo e tecnologias e a produção de narrativas digitais. Currículo sem Fronteiras, v. 12, n. 3, p. 57-82, set./dez. 2012. Disponível em: <http://www.curriculosemfronteiras>. Acesso em: 20 jan. 2017.

\section{AZEVEDO, J. L. A. de. Trabalhando conceitos matemáticos com tecnologias} informáticas por meio da elaboração de projetos de construção civil. 2008. 171f. Tese (Mestrado em Educação Matemática). Universidade Estadual Paulista, Rio Claro, SP, 2008. Disponível em:

<http://repositorio.unesp.br/bitstream/handle/11449/91106/azevedo_jla_me_rcla.pdf?se quence $=1 \&$ isAllowed $=\mathrm{y}>$. Acesso em: 11 jan. 2017.

BAKHTIN, M. Estética da criação verbal. 4. ed. Trad. Paulo Bezerra. São Paulo: Martins Fontes, 2003.

BAKHTIN, M. Marxismo e filosofia da linguagem. Trad. Michel Lahud e yara Frateschi Vieira. 9. ed. São Paulo: Hucitec, 1999.

BENJAMIN, W. Textos Escolhidos. Trad. de Modesto Carone et al. São Paulo: Abril Cultural, 1983.

BRUNER, J. Actos de significado: para uma psicologia cultural. Lisboa: Edições 70, 1990.

BRUNER, J. A Cultura da Educação. Trad. M. A. G. Domingues. Porto Alegre: Artmed, 2001.

CARNEIRO, M. L. F.; GELLER, M.; PASSERINO, L. Navegando em ambientes virtuais: metodologias e estratégias para o novo aluno. Material elaborado para o Curso de Formação em Serviço de Professores e Informática na Educação Especial.

PROINESP/UFRGS. Universidade Federal do Rio Grande do Sul, Porto Alegre, 2005. 
CARVALHO, G. S. (2008). As Histórias Digitais: Narrativas no Século XXI. O Software Movie Maker como Recurso Procedimental para a Construção de Narrações. Dissertação de Mestrado em Educação. São Paulo: Universidade de São Paulo.

CHARTIER, R. (Org.) Práticas da leitura. Trad. Cristiane Nascimento. São Paulo: Estação da Liberdade, 1996.

CHARTIER, R. A aventura do livro: do leitor ao navegador. Trad. Reginaldo de Moraes. São Paulo: UNESP, 1999.

CHARTIER, R. História cultural: entre práticas e representações. Trad. M. M. Galhardo. Lisboa: Difel; Rio de Janeiro: Bertrand Brasil, 2002.

CUNHA, M. I. Aula universitária: inovação e pesquisa. In: LEITE, D., MOROSINI, M. (Org.) Universidade Futurante. Campinas: Papirus, 1997.

FREIRE, P. Pedagogia do oprimido. 17. ed. Rio de Janeiro: Paz e Terra, 1987.

HIRSCHKOP, K. Bakhtin, discurso e democracia. In: Mikhail Bakhtin: Linguagem, Cultura e Mídia. São Carlos: Pedro e João Editores, 2010. 430 p.

LEMKE, J. L. Travels in hypermodality. Visual Communication, 2002.

LÉVY, P. O que é o virtual? São Paulo: Ed. 34, 1996.

LÉVY, P. Cibercultura. Tradução de Carlos Irineu da Costa. São Paulo: Ed. 34, 1999.

MURRAY, H. J. Hamlet no Holodeck. O futuro da narrativa no ciberespaço. Trad. E. K. Daher; M. F. Cuzziol. São Paulo: Itaú cultural: Unesp, 2011.

NUNES, S. da C.; SANTOS, R. P. dos. O Construcionismo de Papert na criação de um objeto de aprendizagem e sua avaliação segundo a taxionomia de Bloom. IX Encontro Nacional de Pesquisa em Educação em Ciências - IX ENPEC, 9., 2013, Águas de Lindóia, SP. Atas.... Disponível em: <http://www.nutes:.ufrj.br/abrapec/ixenpec/atas/resumos/R1200-1.pdf>. Acesso em: 11 jan. 2017

OLIVÉ, L. El livro, la lectura y las bibliotecas em la sociedade del conocimiento. Lectura y vida, Buenos Aires, año 30, n. 3, 2009.

PAIVA, V. Narrativas multimídia de aprendizagem de língua inglesa: um gênero emergente. Anais do 4. ${ }^{\circ}$ Simpósio Internacional de Estudos de Gêneros Textuais, Tubarão: UNISUL, 2007.

PAPERT, S. A máquina das crianças. Porto Alegre: Artmed, 1994.

PAUL, N. Elementos das narrativas digitais. In: FERRARY, Pollyana (org), Hipertexto, hipermídia: as novas ferramentas da comunicação digital. São Paulo: Contexto, 2007. 
PRADO, G. do V. T.; SOLIGO, R. Memorial de formação - quando as memórias narram a história da formação. In: PRADO, G. do V. T.; SOLIGO, R. Porque escrever é fazer história. (Orgs.). Campinas: Graf. FE, 2005, p.47-62.

RIBEIRO, A. E. Ler na tela / letramento e novos suportes de leitura e escrita. In: COSCARELLI, Carla; RIBEIRO, Ana Elisa. Letramento digital: aspectos sociais e possibilidades pedagógicas. 3. ed. Belo Horizonte: Ceake; Autêntica Editora, 2014.

ROBIN, B. R. Digital Storytelling: A Powerful Technology Tool for the 21st Century Classroom. Theory Into Practice, 47(3), pp. 220-228, 2008.

ROBIN, B. R. The Educational Uses of Digital Storytelling. In: CRAWFORD, C. et al. (Eds.), Proceedings of Society for Information Technology \& Teacher Education 125 International Conference, 2006. p. 709-716. Chesapeake, VA: AACE, 2014. Disponível em: 〈http://www.editlib.org/p/2212n9>. Acesso em: 29 jan. 2017.

SANTAELLA, L. Navegar no ciberespaço: o perfil cognitivo do leitor imersivo. São Paulo: Paulus, 2004.

SCHVAMBACH, K. K. Nos tempos antigos... contando nossa história: um projeto interdisciplinar envolvendo produção de narrativas e o uso de TDICs nos anos iniciais do ensino fundamental. 2016. 70. Trabalho de Conclusão de Curso, Especialização em Educação na Cultura Digital, Universidade Federal de Santa Catarina, Florianópolis, SC, 2016. Disponível em:

$<$ https://repositorio.ufsc.br/bitstream/handle/123456789/169038/TCC_Schvambach.pdf ?sequence=1\&isAllowed=y $>$. Acesso em: 12 jan. 2017.

SOARES, M. Novas práticas de leitura e escrita: letramento na cibercultura. Educação e Sociedade, Campinas, v. 23, n. 81, p. 143-160, 2002. Disponível em:

<http://www.scielo.br/pdf/es/v23n81/13935.pdf>. Acesso em: 11 jan. 2017.

SOARES, M. Alfabetização e Letramento: caminhos e descaminhos. Acervo Digital Unesp. fev., 2004. p. 96-100. Disponível em:

<http://www.acervodigital.unesp.br/bitstream/123456789/40142/1/01d16t07.pdf>. Acesso em: 17 jan. 2017.

VALENTE, J.A. A espiral da espiral de aprendizagem: o processo de compreensão do papel das tecnologias de informação e comunicação na educação. 2005. Tese (Livre Docência) Departamento de Multimeios, Mídia e Comunicação, Instituto de Artes (IA), Universidade Estadual de Campinas (UNICAMP). Disponível em:

<http://www.bibliotecadigital.unicamp.br/document/?code=000857072\&opt=4>. Acesso em: 7 jan. 2017.

VALENTE, J. A.; ALMEIDA, M. E. B. (orgs.). Formação de educadores a distância e integração de mídias. São Paulo: Avercamp, 2007.

VALENTE, J. A.; ALMEIDA, M. E. B. As Tecnologias Digitais e os Diferentes Letramentos. Ano IV, n. 15. As diferentes dimensões do aprender, nov. 2000/ jan. 2001. Disponível pelo endereço: 
<http://www.revistapatio.com.br/sumario_conteudo.aspx?id=597>. Acesso em: 29 jan. 2017.

VASCONCELOS, D. C.; MAGALHÃES, H. As Narrativas Multimediáticas das Charges Animadas. Cultura Mediática: Revista do Programa de Pós-Graduação em Comunicação da Universidade Federal da Paraíba. Ano III, n. 1, 2005.

WEBER, M. Professores contadores de histórias. In: FERREIRA, Jacques de Lima (org.). Formação de professores: teoria e prática pedagógica. Petrópolis, RJ: Vozes, 2014.

XAVIER, A. C. dos S. Letramento digital e ensino. 2002. Núcleo de Estudos de Hipertexto e tecnologia Educacional NEHTE. Disponível em:

http://www.ufpe.br/nehte/artigos/Letramento-Digital-Xavier.pdf>. Acesso em: 29 jan. 2017.

\section{Como referenciar este artigo}

PRADO, Ana Lúcia et al. Narrativas digitais: conceitos e contextos de letramento. Revista Ibero-Americana de Estudos em Educação, Araraquara, v. 12, n. esp. 2, p.1156-1176, ago./2017. Disponível em: <http://dx.doi.org/10.21723/riaee.v12.n.esp.2.10286>. E-ISSN: 1982-5587.

Submetido em: 30/03/2017

Aprovação final em: 30/06/2017 